\title{
Potential of Carica papaya peels as effective biocatalyst in the optimized parametric transesterification of used vegetable oil
}

\author{
A.O. Etim ${ }^{1}$, Andrew C. Eloka-Eboka ${ }^{2^{+*}}$, P. Musonge ${ }^{3^{*}}$ \\ ${ }^{1}$ Department of Chemical Engineering, Durban University of Technology, Durban, South Africa \\ ${ }^{2}$ School of Chemical and Minerals Engineering, North West University, Potchefstroom, South Africa \\ ${ }^{3}$ Institute of Systems Science, Durban University of Technology, Durban, South Africa \\ "These authors contributed equally to this work
}

\begin{abstract}
This study investigates the effectiveness of a base heterogenous catalyst derived from waste Carica papaya peels in the transesterification of used vegetable oil (UVO). The calcined Carica papaya peels (CCPP) were characterised using scanning electron microscope-energy dispersive X-ray (SEM-EDX), X-ray diffraction (XRD) and Fourier transform infrared spectroscopy (FT-IR). The EDX result indicated that the ash contains various minerals with potassium $(\mathrm{K})$ as the main active element in remove for the charge of the high catalytic activity. Response surface methodology (RSM) based on the Box Behnken design (BBD) was used to optimise and investigate the effect of the critical process parameters which include: the reaction time $(50-70 \mathrm{~min})$, catalyst loading $(2.5-4.5 \mathrm{wt} \%)$ and methanol-to-oil molar ratio $(9: 1-15: 1)$. The optimal reaction condition for the transesterification process was found to be catalyst loading of $3.5 \mathrm{wt} \%$, methanol/oil molar ratio of 12:1, process reaction time of $60 \mathrm{~min}$ at constant reaction temperature of $65{ }^{\circ} \mathrm{C}$ which resulted in the maximum biodiesel yield of $97.5 \mathrm{wt} \%$. The quality of the produced biodiesel was in agreement with ASTM standards. The catalyst was reused up to three times with minimal decrease in the catalytic activity in the biodiesel conversion. The study demonstrates the potential of waste biomass feedstocks in the production of sustainable biodiesel fuel.
\end{abstract}

Keywords: Biodiesel, Carica papaya peels, Heterogeneous catalysts, Optimization, Used vegetable oil

\section{Introduction}

Global concern over fossil fuel depletion and its contending issues on the environment has led to the exploration of alternative energy resources. Biofuels are an attractive option to overcome these problems as freely available waste biomass materials could be converted into different energy sources through application of chemical and biological technologies. Waste and combustible renewable materials have the potential to supply the global energy demand. These have remained unaccounted for and would have been effective and sustainable energy sources over the last decades. Amongst different types of biofuels, biodiesel is receiving more attraction in view of chemical nature and properties. Its outstanding fuel alternative qualities are obvious in its renewability, non-toxicity, biodegradability, less pollutant in emission and its can be hybridised with the existing petroleum diesel fuel and used with no further engine modification [1]. It is one of the most convenient and promis-

This is an Open Access article distributed under the terms of the Creative Commons Attribution Non-Commercial License (http://creativecommons.org/licenses/by-nc/3.0/) which permits unrestricted non-commercial use, distribution, and reproduction in any medium, provided the original work is properly cited.

Copyright (C) 2021 Korean Society of Environmental Engineers ing energy source among several alternatives identified. Fatty acid methyl ester popularly known as biodiesel, has its source from vegetable oils, micro algae lipids, animal fats, and waste cooking oil. The current trend from a research viewpoint suggests that more improvement in the production process is still required in order to boost biodiesel quality and make competitive its production economics.

Biodiesel is yet to attain its full adoption as a viable alternative fuel, due to the issue of high price. Until this is properly addressed, its full adoption cannot be accomplished. The cost of biodiesel production is linked to the feedstock of its production, as the cost of feedstock account up to $85 \%$ of its total production cost [2]. Effective selection of appropriate feedstock could possibly reduce the overall cost of its production. Waste oil has a potential as an effective feedstock of biodiesel production. It is much cheaper than the virgin vegetable oils and easily obtainable both in cities and villages. Deployment of waste/used oil as main feedstock for
Received June 03, 2020 Accepted September 04, 2020

${ }^{\dagger}$ Corresponding author

Email: fatherfounder@yahoo.com

Tel: +27738257444

ORCID: 0000-0001-7843-8676 
biodiesel production would ensure its price affordability and healthy environment. The catalyst is one of the essential raw materials in biodiesel production. Its production cost and catalytic features determine its adoption and application in industrial scale. Utilization of inexpensive and efficient heterogenous catalysts derived from waste biomass materials in addition to waste cooking vegetable oil for biodiesel production could make the biodiesel production economy attractive and environmentally safe.

Heterogenous catalyst has been proposed in many studies as a potential option for biodiesel industrial production due to its benefits over homogenous catalysts. The preferential option could be seen in many studies via reusability, non-corrosivity, no soap formation, thermally stability and ease of separation [3]. The current trend in heterogenous catalysts development is centred on the conversion of biomass waste to effective solid catalysts for the transesterification process of biodiesel production. This is because these wastes are easily available and the conversion processes are cheap, this can further reduce the cost of biodiesel production. Agricultural waste materials form part of biomass wastes and have been found in various research studies as effective source of heterogenous catalysts for biodiesel production [4]. Table 1 shows various types of agro-waste materials that has been investigated for biodiesel production in recent years. It has been indicated in these studies that waste agro materials are high in potassium content, which is the key element that is responsible for their high catalytic activity in transesterification process of biodiesel production. One of such valuable waste with high content of potassium and efficient catalytic strength is the papaya peels.

Carica papaya commonly known as pawpaw is a member of caricaceae family. It is a herbaceous plant grown in tropical and subtropical regions of the world. Papaya fruit pulp contain carbohy- drate as the major nutritional component. The ripe papaya fruit are freshly consumed globally and are reported to contain high amount of sucrose and some macro and micro minerals such as $\mathrm{K}, \mathrm{Na}, \mathrm{Mg}, \mathrm{Ca}, \mathrm{Mn}, \mathrm{Cu}$ and $\mathrm{Zn}$. Papaya fruit is a good source of carotenoids, vitamin $\mathrm{C}, \mathrm{B}, \mathrm{K}$, thiamine, riboflavin and niacin [5]. The world annual production of papaya fruit in 2017 was 13,016,281 metric tonnes and South Africa has very little production due to non-ideal climatic challenge for its production. With this enormous production of papaya fruit, disposal of peels becomes a major challenge as it contributes to environmental waste pollution. Apart from the utilization of the peels as food additives and supplements, information are dearth regarding other industrial utilization of the peels. It is reported that the peels contains potassium as the major ingredient in its mineral composition up to 504.33 $516.33 \mathrm{mg} / \mathrm{kg}$ with other element such as Ca (16.23 mg/kg), Zn (1.93 $\mathrm{mg} / \mathrm{kg}$ ) and Fe $(2.73 \mathrm{mg} / \mathrm{kg}$ ) [5, 6]. However, the presence of a high content of potassium suggests that it could be developed as a catalyst for transesterification processes.

Response surface methodology (RSM) is a statistical method that uses quantitative data from a well-designed experiment to solve multivariant equations [7]. It is widely used by researchers due to its versatility in various processes and for optimisation. RSM describes the functional relationship between the input variables and the responses using experimental data. It gives the advantage of optimizing the multifactor problems with optimum number of experimental runs and allows for an understanding of the interaction between the experimental process variables [8]. The use of RSM has successfully eliminated the method of optimization based on one factor at a time (OFAT) which is considered time consuming, by simultaneously modelling the individual and combined effect of factors affecting the response. Box Behnken design

Table 1. Various Types of Agricultural Waste Materials Recently Investigated as Catalysts for Biodiesel Production

\begin{tabular}{|c|c|c|c|c|c|c|c|c|}
\hline $\begin{array}{l}\text { Agro-waste } \\
\text { material }\end{array}$ & $\begin{array}{c}\text { Temp of } \\
\text { Calcination }\end{array}$ & $\begin{array}{l}\text { Key elements } \\
\text { content }\end{array}$ & $\begin{array}{c}\text { Methanol/ } \\
\text { oil Ratio }\end{array}$ & $\begin{array}{c}\text { Catalyst loading } \\
\text { (wt } \%)\end{array}$ & $\begin{array}{l}\text { Time } \\
(\mathrm{min})\end{array}$ & $\begin{array}{c}\text { Temp } \\
\left({ }^{\circ} \mathrm{C}\right)\end{array}$ & $\begin{array}{c}\text { Yield } \\
\text { (\%) }\end{array}$ & Ref. \\
\hline $\begin{array}{l}\text { Tectona grandis } \\
\text { leaves }\end{array}$ & $700^{\circ} \mathrm{C}, 4 \mathrm{~h}$ & $\begin{array}{c}\mathrm{K}(53.25), \mathrm{Ca}(30.28) \\
\mathrm{Si}(10.03)\end{array}$ & $6: 1$ & 2.5 & - & 25 & 100 & {$[11]$} \\
\hline Tucuma peels & $800^{\circ} \mathrm{C}, 4 \mathrm{~h}$ & $\begin{array}{c}\mathrm{K}(69.81), \mathrm{P}(12.67) \\
\mathrm{Mg}(6.67)\end{array}$ & $15: 1$ & 1.0 & 240 & 80 & 97.3 & {$[12]$} \\
\hline $\begin{array}{l}\text { Waste Brassica } \\
\text { nigra plant }\end{array}$ & $550^{\circ} \mathrm{C} 2 \mathrm{~h}$ & $\mathrm{~K}(56.13), \mathrm{Ca}(26.04)$ & $12: 1$ & 7 & 25 & 65 & 98.79 & {$[13]$} \\
\hline Banana peels & $700^{\circ} \mathrm{C}, 4 \mathrm{~h}$ & $\mathrm{~K}(99.73), \operatorname{Mg}(0.03)$ & $7.6: 1$ & 2.75 & 69.02 & 65 & 98.5 & {$[14]$} \\
\hline $\begin{array}{l}\text { Ripe Plantain } \\
\text { peels }\end{array}$ & $700^{\circ} \mathrm{C}, 4 \mathrm{~h}$ & $K(51.02), \operatorname{Si}(2.51)$ & $0.73 \mathrm{v} / \mathrm{v}$ & 0.65 & 57 & 65 & 99.2 & {$[15]$} \\
\hline $\begin{array}{l}\text { Red banana } \\
\text { peduncle }\end{array}$ & $700^{\circ} \mathrm{C}, 4 \mathrm{~h}$ & $\begin{array}{c}\mathrm{K}(68.37), \mathrm{Ca}(7.09) \\
\operatorname{Mg}(4.66)\end{array}$ & $9.20: 1$ & 1.98 & 60 & 60 & 98.69 & [2] \\
\hline $\begin{array}{l}\text { Kola nut pod } \\
\text { husk }\end{array}$ & $500^{\circ} \mathrm{C}, 4 \mathrm{~h}$ & $\begin{array}{c}\mathrm{K}(47.14), \operatorname{Mg}(5.35) \\
\mathrm{P}(2.31)\end{array}$ & $6: 1$ & 3.0 & 75 & 65 & 98.67 & {$[4]$} \\
\hline $\begin{array}{l}\text { Waste S. } \\
\text { indicum plant }\end{array}$ & $550^{\circ} \mathrm{C}, 2 \mathrm{~h}$ & $\mathrm{~K}(29.64), \mathrm{Ca}(33.80)$ & $12: 1$ & 7.0 & 40 & 65 & 98.9 & {$[16]$} \\
\hline Coco pod husk & $700^{\circ} \mathrm{C}, 4 \mathrm{~h}$ & $\mathrm{~K}(59.2), \operatorname{Mg}(3.0)$ & $0.73: 1 \mathrm{v} / \mathrm{v}$ & 0.6 & 57 & 65 & 99.3 & {$[17]$} \\
\hline $\begin{array}{l}\text { Carica papaya } \\
\text { peels }\end{array}$ & $700^{\circ} \mathrm{C}, 3 \mathrm{~h}$ & $\begin{array}{c}\mathrm{K}(30.74), \mathrm{Cl}(10.3), \\
\mathrm{S}(4.31), \mathrm{P}(3.64)\end{array}$ & $12: 1$ & 3.5 & 60 & 65 & 97.5 & Present study \\
\hline
\end{tabular}


(BBD) of the RSM provides the advantage of optimizing the multifactor problems with minimum number of experimental conditions and allow for interaction between the experimental process variables. It has been applied in various studies to identify the optimum conditions and to investigate the effect of controllable parameters in transesterification experiments [8-10].

This study therefore aims to explore and clarify the utilization of Carica papaya peels as effective heterogenous catalyst for biodiesel synthesis from used vegetable oil via the transesterification process with a view to optimize the process parameters using RSM and $\mathrm{BBD}$, and also to study the pattern effect of the process parameters on the response. The overall aim of this study is to contribute to the development of cost-effective and sustainable biodiesel production catalysts from available biomass waste materials. This in addition to the ones listed in Table 1 and many others will contribute in addressing fossil fuel contending issues and utilisation of biomass waste in the green bioenergy economy.

\section{Experimental}

\subsection{Materials and Reagents}

The Carica papaya fruit was obtained from a local fruit market at Mushin, Lagos, Nigeria and the peels removed was utilized in this study. The used frying oil was obtained from the students' cafeteria in Steve Biko campus, Durban University of Technology, Durban, South Africa. All chemical reagents such as methanol (98\%), ethanol (98\%), potassium hydroxide, diethyl ether, cyclohexane, potassium iodide, chloroform, phenolphthalein (indicator) were purchased from United Scientific SA, Congella, South Africa. All chemical reagents used in this work were of analytical grades

\subsection{Methods}

\subsubsection{Preparation of the bio-solid catalyst}

The ripe Carica papaya peels (CPP) obtained were washed three times with tap water to ensure that all the impurities were removed. The washed peels were cut into pieces to allow for easy drying and then sun-dried for 2 weeks. The dried papaya peels were burnt in open air to generate ash which was then milled to powder. The powder obtained was sieved to fine particles $(>0.5 \mathrm{~mm})$ to get burnt Carica papaya peels (BCPP). The sieved fine ash was further calcined at $700^{\circ} \mathrm{C}$ for $4 \mathrm{~h}$ in a muffle furnace (Havells, B 25, DHMCBSPF025) [16-18]. The calcined ash was then pulverised using an agate mortar and pestle to obtain calcined Carica papaya peels (CCPP). Both BCPP and CCPP were properly kept in a desiccator for further use and analysis.

\subsubsection{Characterization of the catalyst from the papaya peels}

The active surface functional groups present in BCPP and CPPA samples were determined by fourier transform infrared (FT-IR) analysis using PerkinElmer 100 FT-IR spectrophotometer. The samples were characterized at the wave number range of $4000-500$ $\mathrm{cm}^{-1}$. X-ray diffraction (XRD) was used to obtain information regarding crystallinity of the samples. This was done by D-8 Advanced (Bruker AXS Karlsruhe, Germany) diffractometer using $\mathrm{Cu}-\mathrm{K} \alpha$ radiation $(\lambda=1.5406 \AA$ ) equipped with (PSD) detector at $40 \mathrm{kV}$ and
$30 \mathrm{~mA}$, in the scanning angle of $2 \Theta$ ranging between 10 to $80^{\circ}$. A high-resolution scanning electron microscope (SEM) by AURIGA (Zeiss Germany) fitted to the energy dispersive X-ray (EDX) detector was used to obtain the surface morphology and elemental composition of the BCPP and CCPP samples.

\subsection{Experimental Design for the Transesterification Process}

The modelling and optimization of the transesterification was investigated using BBD based on RSM. BBD provides the advantage of optimizing the multifactor problems with an optimum number of experimental condition and allows for interaction between the experimental process variables. BBD are useful in estimating quadratic model parameters and building of progressive designs [9]. BBD has been applied successfully in various transesterification reaction processes to investigate the effect of process variables and to determine the optimal conditions with a reduced number of experiments [10, 19, 20]. It has been applied by [9] to optimized biodiesel production from Portulaca seed oil and to investigate the effective variables with the predicted optimum yield of $97.81 \%$. BBD was used successfully to optimise the effect of the process variables and to determine the optimum condition in biodiesel production from soybeans oil by [10] and a maximum yield of $98 \%$ was reported. BBD has also been used to investigate the relationship of the operating parameters and to obtain the optimum condition in palm oil biodiesel production using heterogenous catalyst and a high percentage of FAME was achieved [21].

In this study, a three level three factor BBD was used to produce 17 experimental runs which was subsequently carried out in the laboratory. The independent factors selected for the optimization include reaction time, catalyst loading levels and methanol-to-oil molar ratio. The process reaction temperature and agitation speed were held constant at $65^{\circ} \mathrm{C}$ and $600 \mathrm{rpm}$ to ensure proper mixing $[18,22]$. The experimental conditions were randomized in order to reduce the impact of unexpected variability in the actual responses. Table 2 Shows the levels of coded and uncoded values of the independent variables while the BBD of the experimental conditions are shown in Table 3. The coefficients of the quadratic polynomial model of the responses were fitted using multiply regression. The quality of fit of the model were assessed using the test of significance and the analysis of variance (ANOVA). The equation that described the fitness of the model is given in Eq. (1).

$$
Y=\beta_{0}+\sum_{i=1}^{n} \beta_{i} Z_{i}+\sum_{i=i}^{n} \beta_{i i} Z_{i}^{2}+\sum_{i=1}^{n-1} \sum_{j=2}^{n} \beta_{i j} Z_{i} Z_{j}+h
$$

Where $\mathrm{Y}$ is the biodiesel yield, $\beta_{0}$ is the intercept, $\beta_{\mathrm{i}}$ is the first order coefficient, $\beta_{\mathrm{ii}}$ is the quadratic coefficient, $\beta_{\mathrm{ij}}$ and $\mathrm{Z}_{\mathrm{ij}}$ is the interaction effect coefficient and $h$ is the random error.

\subsubsection{Transesterification of UVO using CCPP}

The used vegetable oil (UVO) used in this work has a high viscosity of $33.0 \mathrm{cSt}$ and acid value of $1.25(\mathrm{mg} / \mathrm{KOH} / \mathrm{g})$. The corresponding FFA of $0.63 \%$ suggest a one-step transesterification to convert it to biodiesel using a base catalyst [12]. 
Table 2. Process Parameters and Values Considered at Different Levels

\begin{tabular}{lcccc}
\hline \multirow{2}{*}{ Factors } & \multirow{2}{*}{ Symbols } & \multicolumn{3}{c}{ Coded factor levels } \\
\cline { 3 - 5 } & & $\mathbf{- 1}$ & $\mathbf{0}$ & $\mathbf{1}$ \\
\hline Reaction time (min) & $\mathrm{Z} 1$ & 50 & 60 & 70 \\
Catalyst loading (wt\%) & $\mathrm{Z} 2$ & 2.5 & 3.5 & 4.5 \\
Methanol/oil molar ratio & $\mathrm{Z} 3$ & $9: 1$ & $12: 1$ & $15: 1$ \\
\hline
\end{tabular}

The transesterification process of UVO with calcined (CCPP was carried out using a batch-scale laboratory glass reactor of 500-ml three-necked round bottom flask, equipped with a condenser and placed on a magnetic stirring hot plate. In accordance with the different set of process parameters established by the Box Behnken Design as depicted in Table 3 specified amount of UVO was poured carefully into the reactor and a known volume of methanol was added, after which the mixture was allowed to stir for $5 \mathrm{~min}$. A weighed amount of calcined CCPP was added and the reaction was allowed to reach completion according to the stipulated time on the design guide (Table 3). A constant temperature of $65^{\circ} \mathrm{C}$ and stirring speed of $600 \mathrm{rpm}$ were maintained throughout the reaction period $[17,18]$. At the end of the reaction, various fractions of the product were allowed to settle by gravitation with the aid of separatory funnels forming three layers (Biodiesel, glycerol and catalyst layers), arranging in the order of their densities. The downstream layers (i.e. the catalyst and glycerol layers) were removed. The top layer which is the biodiesel was purified by wet washing with warm distilled water at $50^{\circ} \mathrm{C}$ and heated to remove excess methanol and the residual catalyst, soap and glycerol [4]. The purified used vegetable oil methyl ester (UVOME) yield was calculated using Eq. (2).

$$
\text { UVOME }=\frac{\text { weight of methyl ester produced }}{\text { weight of oil sample used }} \times 100
$$

The UVOME produced were characterized by determining their physiochemical properties which include; moisture content, density, viscosity, acid value, free fatty acid, saponification value iodine value, cetane number and calorific value according to AOAC and ASTM methods.

\section{Result and Discussion}

\subsection{Characterization of CCPP Catalyst}

3.3.1. Elemental characterization and morphological investigations In the development of important base elements or metals in biomass materials, heat treatment at high temperature is the crucial factor [3]. Thermal treatment is used in order to improve the catalytic content of the biomass materials which are useful in the conversion of oils to fatty acid methyl esters. Thermal treatment in form of calcination is cheaper and simple to operate when compared to other forms such as carbonization which requires to be operated in a nitrogen gas environment. But open air burning has been employed by some researchers for the preparation of the biomass materials before calcination. The process according to them allows for easy/quicker heat absorption within a shorter time at high temperatures and also increases the porosity of catalysts [3, 4, 15-17, $23,24]$. Calcination process enriched the mesoporous and microporous structure of the catalyst to enhanced its surface area and increase its catalytic activity [18]. In addition, Etim et al. [3] reported that the calcination at high temperatures enables the reusability

Table 3. Experimental Matrix and UVOME Yield for Transesterification Process

\begin{tabular}{|c|c|c|c|c|c|c|}
\hline Standard order & Run & $\mathrm{Z}_{1}$ & $\mathrm{Z}_{2}$ & $\mathrm{Z}_{3}$ & UVOME & RSM Prediction \\
\hline 17 & 1 & $60(0)$ & $3.5(0)$ & $12(0)$ & 94.50 & 96.06 \\
\hline 1 & 2 & $50(-1)$ & $2.5(-1)$ & $12(0)$ & 89.50 & 89.25 \\
\hline 7 & 3 & $50(-1)$ & $3.5(0)$ & $15(1)$ & 89.30 & 88.99 \\
\hline 5 & 4 & $50(-1)$ & $3.5(0)$ & $9(-1)$ & 81.60 & 81.79 \\
\hline 14 & 5 & $60(0)$ & $3.5(0)$ & $12(0)$ & 96.50 & 96.06 \\
\hline 11 & 6 & $60(0)$ & $2.5(-1)$ & $15(1)$ & 87.10 & 87.66 \\
\hline 16 & 7 & $60(0)$ & $3.5(0)$ & $12(0)$ & 96.50 & 96.06 \\
\hline 4 & 8 & $70(1)$ & $4.5(1)$ & $12(0)$ & 90.00 & 90.25 \\
\hline 3 & 9 & $50(-1)$ & $4.5(1)$ & $12(0)$ & 85.40 & 85.78 \\
\hline 9 & 10 & $60(0)$ & $2.5(-1)$ & $9(-1)$ & 83.50 & 83.56 \\
\hline 13 & 11 & $60(0)$ & $3.5(0)$ & $12(0)$ & 97.50 & 96.06 \\
\hline 2 & 12 & $70(1)$ & $2.5(-1)$ & $12(0)$ & 88.80 & 88.43 \\
\hline 15 & 13 & $60(0)$ & $3.5(0)$ & $12(0)$ & 95.30 & 96.06 \\
\hline 6 & 14 & $70(1)$ & $3.5(0)$ & $9(-1)$ & 87.30 & 87.61 \\
\hline 12 & 15 & $60(0)$ & $4.5(1)$ & $15(1)$ & 86.00 & 85.94 \\
\hline 8 & 16 & $70(1)$ & $3.5(0)$ & $15(1)$ & 87.00 & 86.81 \\
\hline 10 & 17 & $60(0)$ & $4.5(1)$ & $9(-1)$ & 84.20 & 83.64 \\
\hline
\end{tabular}


of the catalyst and prevents leaching. Lack of higher heat temperature on biomass materials leads to quick deactivation of the catalysts as a result of leaching of the active elements into the biodiesel product [25].

\subsubsection{EDX analysis}

The EDX analysis provides the quantitative compositions of elements present in the burnt and calcined papaya peels samples and the results are presented in Table 4 . The results revealed the significant effect of the calcination temperature on the elemental composition of CCPP. It could be seen from the table that carbon and oxygen content are found only in BCPP sample but absent in CCPP sample. This could be attributed to reduction of carbon and oxygen at high thermal treatment to form metal oxides [3, 26]. A similar observation was also reported by [4, 17, 24, 26, 27]. The effect of calcination temperature on biomass materials has been reviewed and reported by [3]. The temperature of calcination $\left(700^{\circ} \mathrm{C}\right)$ and time $(4 \mathrm{~h})$ used in the study was selected based on the reported range given in Table 1. Excessive temperature of calcination of the biomass materials reduces the alkaline content of the ash, leading to a decrease in the low activity of the catalyst $[3,4]$. Although the elemental composition analysis of the fresh papaya peels was not considered in this study, it has been reported elsewhere that the approximate compositions of mineral elements of the fresh peels increases in the order $\mathrm{K}>\mathrm{P}>\mathrm{Ca}>\mathrm{Mg}>$ $\mathrm{Na}>\mathrm{Si}>\mathrm{Cu}>\mathrm{Zn}[5,28]$, with $\mathrm{K}$ being the main element. This has also been supported by similar observation from fresh papaya stem composition reported by [29]. The EDX plot illustration of the elements and their percentage compositions of BCPP and CCPP are also shown in Fig. 1. It is acceptable to suggest that $\mathrm{K}$ is the vital active element in CCPP that is responsible for its excellent catalytic activity in UVOME production which is also supported by the XRD and FT-IR characterization results. K has been pinpointed as having the highest strength among other elements in various biomass materials reported in Table 1. The conclusion has also been that $\mathrm{K}$ is the main active ingredient responsible for the catalytic activity in the biodiesel synthesis of their respective oils $[2,12,15,17,27,30] . \mathrm{K}$ in the form of $\mathrm{K}_{2} \mathrm{O}, \mathrm{KCl}$ and $\mathrm{K}_{2} \mathrm{CO}_{3}$ has been reported as the key component with high active sites responsible for the high catalytic activity in bio-catalyst derived from waste brassica nigra plant [13]. It has also been reported in the catalyst derived from waste sesamum indica that $\mathrm{K}$ in the form of $\mathrm{KCl}, \mathrm{K}_{2} \mathrm{CO}_{3}$ and $\mathrm{K}_{2} \mathrm{O}$ are the main components with high basic sites responsible for the high catalytic performance of the catalyst in biodiesel production [16]. In calcined banana peduncle, $\mathrm{K}_{2} \mathrm{O}$ was outlined the active species behind the good performance of the catalyst. In plantain peel derived catalysts, $\mathrm{K}$ was reported in the form of $\mathrm{KCl}, \mathrm{KNaSO}_{4}$ and $\mathrm{K}_{2} \mathrm{MgSiO}_{4}$ as the components with high active sites responsible for the activity of the catalyst [15]

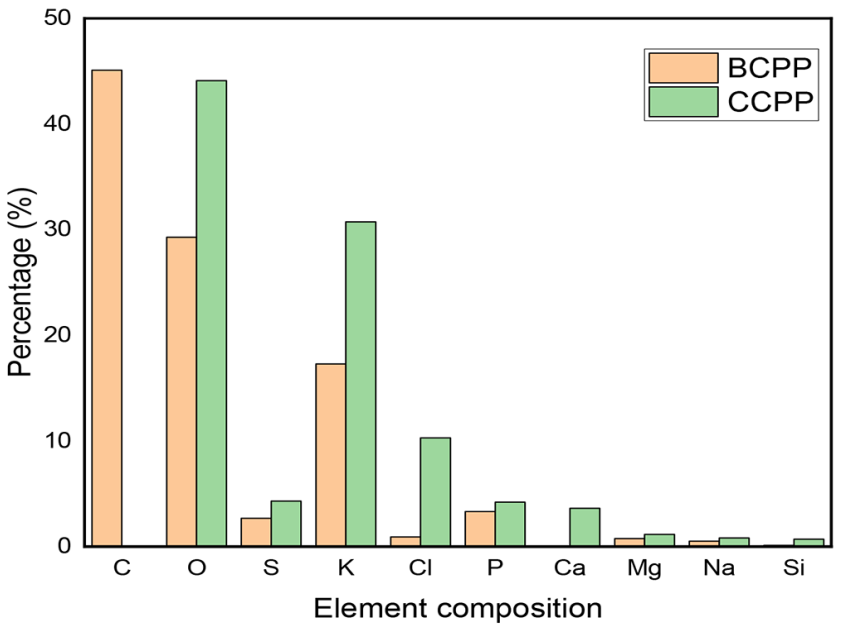

Fig. 1. EDX Plot of elemental compositions for BCPP and CCPP samples.

\subsubsection{SEM analysis}

The scanning electron microscope (SEM) image of the BCPP and CCPP are shown in Fig. 2 (a), (b). The morphological features of the samples were studied at $5 \mu \mathrm{m}$ magnification. In BCPP micrograph (Fig. 2 (a)), a porous morphological nature with mineral aggregate was observed, while the CCPP (Fig. 2 (b)) image showed increase and definite micropores of the particles, clusters in irregular shape and size on the surface. The microstructure of the particles are indicated to be responsible for the improved surface area of the material [31]. The image also demonstrated the porous and spongy nature of particles which are characterized by increase particles agglomeration due to sintering of metal oxides as a result of calcination effect. The fibrous and mesoporous nature of the samples with smaller aggregate of the particles occur due to effect of heat treatment. Other biomass SEM images has also been reported to exhibit similar morphological structures such as wood ash [32, 33], waste brassica nigra plant [13], banana peels [34], coco pod husk [17] and tucuma peels [12].

The FT-IR spectra for the burnt and calcined (CPP) samples are depicted in Fig. 3. which shows several adsorption peaks. The clear bands seen between $3,004 \mathrm{~cm}^{-1}$ to $2,986 \mathrm{~cm}^{-1}$ are attributed to the stretching vibration of O-H group of moisture absorbed at the surface [4], which appears to be more pronounced in the burnt sample than the calcined sample. The observed band at 1,474 $\mathrm{cm}^{-1}, 1,396 \mathrm{~cm}^{-1}$ and $1,394 \mathrm{~cm}^{-1}$ are assigned to $\mathrm{C}-\mathrm{O}$ stretching and bending vibrations, which is indicative of the presence of carbonate $\left(\mathrm{CO}_{3}\right)$. The prominent bands at $1,045 \mathrm{~cm}^{-1}$ and 1,000 $\mathrm{cm}^{-1}$ are attributable to the carbonyl vibration of metal carbonate of $\mathrm{K}_{2} \mathrm{CO}_{3}$ which occur due to the carbonates adsorbed by the metal oxide from the atmosphere onto exposure [29]. The band is strongly

Table 4. Percentage of Elemental Compositions of BCPP Ash

\begin{tabular}{lccccccccccc}
\hline & \multicolumn{10}{c}{ Composition (\%) $@ \mathbf{7 0 0}{ }^{\circ} \mathbf{C}$} \\
\cline { 2 - 10 } & $\mathbf{C}$ & $\mathbf{O}$ & $\mathbf{N a}$ & $\mathbf{M g}$ & $\mathbf{S i}$ & $\mathbf{P}$ & $\mathbf{S}$ & $\mathbf{K}$ & $\mathbf{C l}$ & $\mathbf{C a}$ \\
\hline CCPP & - & 44.1 & 0.82 & 1.16 & 0.71 & 4.22 & 4.31 & 30.74 & 10.3 & 3.64 \\
BCPP ash & 45.09 & 29.28 & 0.53 & 0.76 & 0.13 & 3.32 & 2.68 & 17.29 & 0.92 & - \\
\hline
\end{tabular}



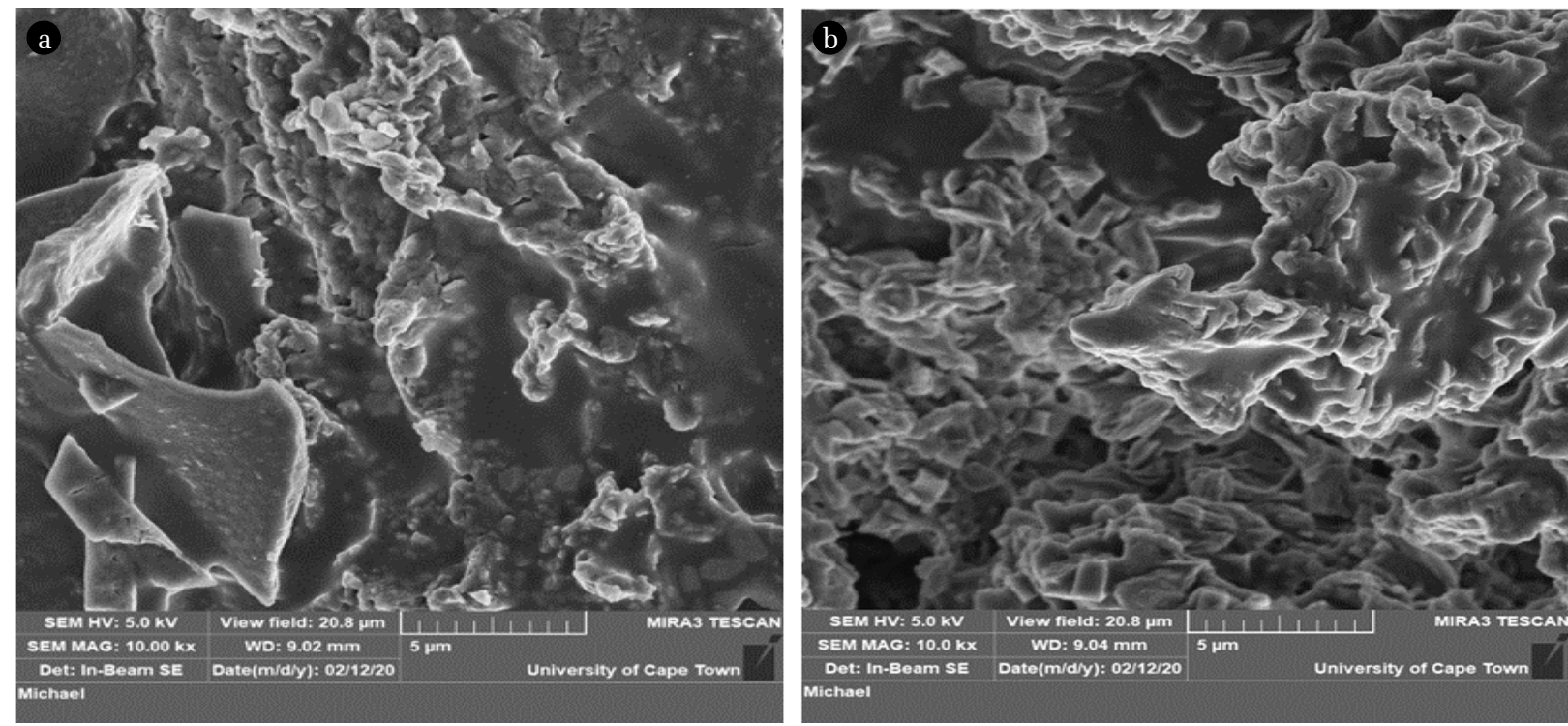

Fig. 2. SEM analysis of (a) BCPP and (b) CCPP.

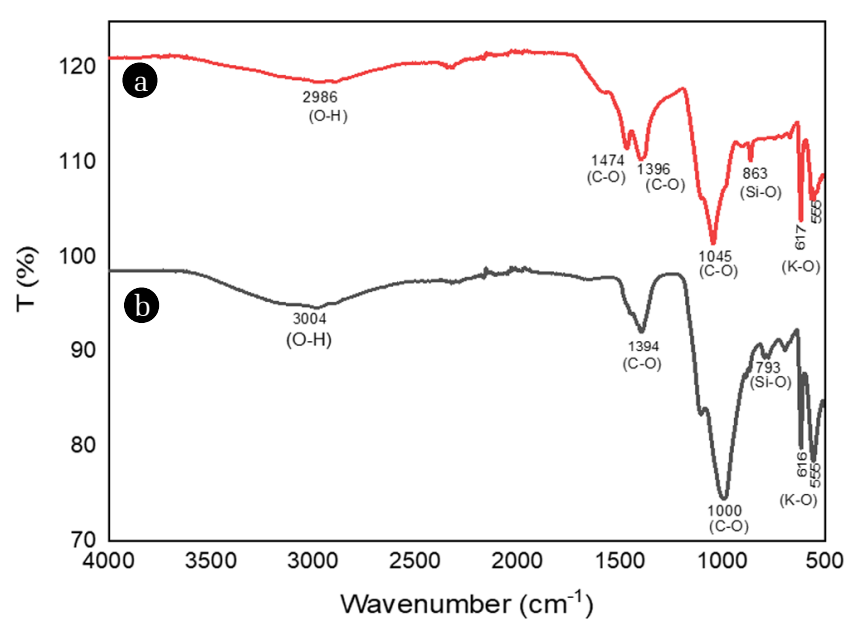

Fig. 3. FT-IR spectra of (a) BCPP and (b) CCPP.

visible in CCPP due to effect of high heat treatment which has also been reported by [17, 32]. The characteristic vibration bands at $863 \mathrm{~cm}^{-1}$ and $793 \mathrm{~cm}^{-1}$ are accredited to Si-O bonds. The bands at $617 \mathrm{~cm}^{-1}, 616 \mathrm{~cm}^{-1}$ and $555 \mathrm{~cm}^{-1}$ are indicative of the stretching vibration of $\mathrm{Ca}-\mathrm{O}$ and $\mathrm{K}-\mathrm{O}$ bonds $[11,30]$, and are stronger in the calcined sample due to heat treatment. The bands observed in this present work has been reported in the calcined ashes of banana peduncle [2], tucuma peels [12], Musa acuminata peels [30], waste sesamum plant [16], coco pod husks [17] and plantain peels [15].

XRD diffractograms of the BCPP and CCPP samples are shown in Fig. 4. The intensity of the peak increased as the applied heat of calcination increases thus this clearly defined the crystallinity of the samples. This observation has been reported in the studies of other biomass catalysts such as ripe plantain peels [15], tucuma peels [12] and kola nut pod husk [4]. The result shows that the major compounds present in CCPP were $\mathrm{KCl}, \mathrm{K}_{2} \mathrm{SO}_{4}$ and $\mathrm{KCaPO}_{4}$.

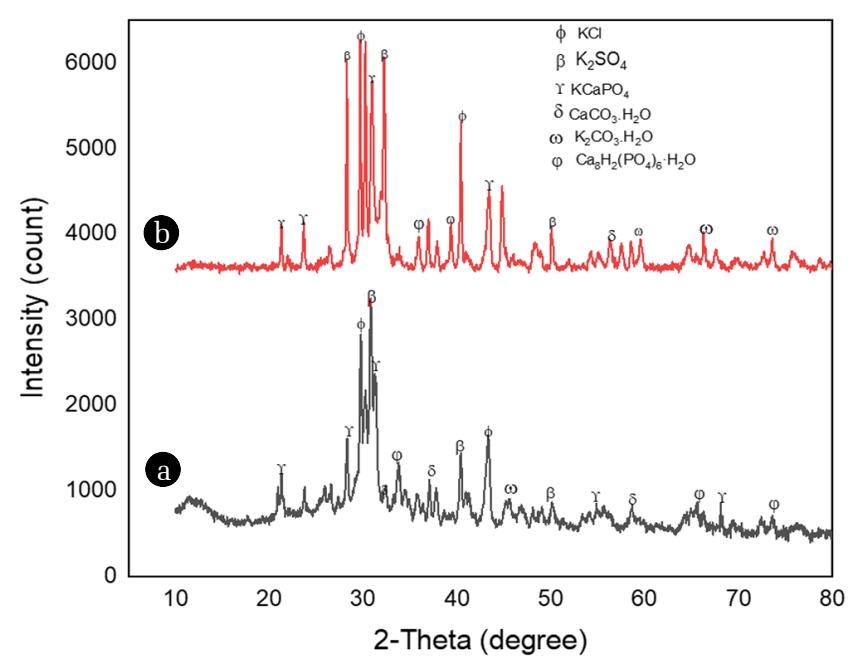

Fig. 4. The XRD of (a) BCPP and (b) CCPP .

The results of the FT-IR, EDX and XRD are all in agreement that $\mathrm{K}$ is the main metallic element present in CCPP, which has been indicated to have an excellent catalytic behaviour in biodiesel production [15, 17, 34].

\subsection{Modelling and Optimization Process of UVOME Synthesis}

The actual and predicted values of UVOME yield and all the variables investigated are given in actual and coded form in Table 3. The UVOME yield ranges from 81.60 to 97.5 wt\%. Eq. (3) represent the surface response quadratic model for the transesterification process.

$$
\begin{gathered}
\text { UVOME }=96.06+0.9125 Z_{1}-0.4125 Z_{2}+1.60 Z_{3}+1.32 Z_{1} Z_{2}- \\
2.00 Z_{1} Z_{3}-0.4500 Z_{2} Z_{3}-3.27 Z_{1}^{2}-4.37 Z_{2}^{2}-6.94 Z_{3}^{2}
\end{gathered}
$$

Where $Z_{1}$ is the reaction time, $Z_{2}$ is the catalyst loading and 
$\mathrm{Z}_{3}$ is the methanol/oil molar ratio.

Analysis of variance (ANOVA) was used to analyse the linear, interactive and quadratic relationship of the effect of independent variables on the yield and it is shown in Table S1. The resultant $P$-value was used to assess the significance of each parameter, the F-value of 44.36 and the P-value of $<0.0001$ implies that the model is significance. P-value greater than $0.05(>0.05)$ shows that the model is not significance@ @ $5 \%$ difference while a value less than $0.05(<0.05)$ indicate that the model is significance. In this case at $95 \%$ confidence level $(p<0.05)$ of all the terms were significant except catalyst loading $\left(\mathrm{Z}_{2}\right)$ and they all demonstrate a favourable effect on the UVOME yield. In addition, the lack of fit (p-value of 0.8120) implies that the fitness is not significant relative to the pure error, and non-significance is desirable for the perfect fitness of the model [35]. Fig. S1 illustrates the parity plot which graphically shows the relationship between the predicted and the actual values, which also demonstrates the significance and the goodness of fit of the model.

\subsection{Interactive Effect of the Process Variables on UVOME Yield}

The effect of interactions of the three process independent variables of CCPP-catalysed transesterification on yield were examined graphically using three dimensional plots and are depicted in Fig. S2 (a)-(c). The surface plot describes how the biodiesel yield varies with changes in experimental conditions. The plot also enables easy identification of the optimum operating condition with the related response.

The effect of interaction between reaction time and catalyst loading is shown in Fig. S2 (a). The effect of reaction time was studied from the range of $50-70$ mins while catalyst effect was observed from the range of $2.5-4.5 \mathrm{wt} \%$ at constant temperature of $65^{\circ} \mathrm{C}$ for all conditions. The interaction term $\left(Z_{1} Z_{2}\right)$ in Table 4 , the p-value of 0.0310 indicates that both terms have significant effects on UVOME yield. The surface plot in Fig. S2 (a) showed that UVOME yield increases with increasing time from $50 \mathrm{~min}$ up to 60 mins where it reaches the optimum and then reduces afterward. In transesterification, sufficient time is required to allow for adequate interaction between the reactants and the catalyst. The UVOME yield attained the highest at 60 min reaction and since transesterification is a reversible reaction, extending the reaction time beyond 60 min optimum decreases UVOME yield due to backward reaction of the transesterification [18]. The catalyst was also observed to increase with increasing yield up to $3.5 \mathrm{wt} \%$ where UVOME yield was maximum, further loading beyond optimum also favours the backward reaction which is soap formation. Thus, similar trend has been observed and reported by [9] in the optimization of biodiesel from Portulaca seed oil and [15] also reported the similar observation in neem oil biodiesel optimization.

Fig. S2 (b) represents the influence of methanol molar ratio and catalyst (CCPP) loading on UVOME yield. Methanol to oil molar ratio is one of the factors that influence biodiesel yield in the transesterification process. The methanol to oil ratio used in this work was studied at the range of 9:1 - 15:1. However, the range is higher than the theoretical ratio of 3:1 [36]. This was required to force the equilibrium reaction to completion in favour of the forward reaction which is UVOME yield. It is shown from the figure that UVOME yield increases with increase of the methanol ratio from 9: 1 up to 12:1 where it attains optimum and afterward reduces with increase in the ratio up to 15:1. The reduced yield at 15:1 molar ratio might be attributed to reverse transesterification which occur at higher methanol ratio leading to soap formation and yield reduction [18]. A similar observation has been reported in transesterification of neem seed oil [15]. Also, the catalyst loading level was studied at varying range of $2.5-4.5 \mathrm{wt} \%$. Excess catalyst loading encourages higher viscosity of the reaction mixture, resulting in poor mixing which leads low to a biodiesel yield [37]. The surface plot shows that UVOME yield started increasing with an elevation of catalyst loading level from $2.5 \mathrm{wt} \%$ up to $3.5 \mathrm{wt} \%$; it thereafter reduces at higher increase level. The reduction in yield at further increasing load levels of the CCPP might be due to poor contact between the methanol and catalyst which is caused by the flow in mass transfer restriction [4]. This trend has also been observed in literature [4, 14]. FAME yield was reported to reduce when calcined banana peels catalyst was increased beyond optimum level of $3.5 \mathrm{wt} \%$ in biodiesel production from Napoleon's plume oil [14]. In biodiesel production from Kariya seed oil (KSO) using kola nut pod husk, it was also reported that FAME yield decreases at increase of catalyst beyond 3 wt\% optimum level. The optimum UVOME yield was observed at methanol to oil molar ratio of 12:1, catalyst loading of $3.5 \mathrm{wt} \%$ and the reaction time of $60 \mathrm{~min}$ (Table 2). However, the combined effect of interaction of the methanol to oil molar ratio and catalyst loading $\left(\mathrm{Z}_{2} \mathrm{Z}_{3}\right)$ in Table 4, the p-value of 0.3910 indicates that this interaction terms had no significant effect on UVOME yield. The observation of a similar trend of methanol oil ratio and catalyst concentration has been reported by [9, 38].

The interaction of methanol to oil molar ratio and reaction time on UVOME yield is shown in Fig. S2 (c). The p-value of the interaction term $Z_{1} Z_{3}$ was found to be 0.0048 , which also attest of the strong interaction of both terms on the yield (Table 4). However, UVOME yield is increased with increasing time and reaches its maximum at $60 \mathrm{~min}$ and then followed by a decreases with the extension of reaction time. Methanol to oil ratio beyond the stoichiometric amount is required to shift the equilibrium of the reversible transesterification reaction towards biodiesel formation. Therefore, in this work, adequate time was required to allow for interaction of the reactant to form a product. The strong influence of methanol to oil, catalyst loading and reaction time on biodiesel yield have been reported [17, 22].

\subsection{Process Parameters Optimization for Maximum UVOME Yield}

The optimal condition for the transesterification process of UVOME yield was obtained from the quadratic regression model established using the Box Behnken design. The optimal values for the three parameters were obtained at methanol/UVO molar ratio of 12:1, CCPP loading level of $3.5 \mathrm{wt} \%$, reaction time of $60 \mathrm{~min}$ and a constant temperature of $65^{\circ} \mathrm{C}$. The actual value obtained for UVOME yield was 97.50 wt\% while the predicted value obtained from RSM was 96.06 wt\% yield. The biodiesel yield obtained in this work compares favourably with the yield of various biomass catalysts 
reported in literature (Table 1). A high yield value of $99.2 \%$ from neem seed oil conversion with ripe plantain peels heterogenous catalyst, under mild operating condition was reported [15]. The yield of $97.3 \%$ was reported when tucuma peels derived heterogenous catalyst was used to transesterify soybeans oil, at methanol to oil molar ratio of $15: 1$, reaction time of $4 \mathrm{~h}$, temperature $80^{\circ} \mathrm{C}$ and catalyst loading of $1 \mathrm{wt} \%$ [12]. 98.73\% yield was reported with red banana peduncle derived heterogenous catalyst, in transesterification of Ceiba pentandra oil at a longer reaction time of $160 \mathrm{~min}$, methanol to oil molar ratio of $11.4: 1$, catalyst loading of $2.68 \mathrm{wt} \%$ and temperature of $65^{\circ} \mathrm{C}$ [2]. $91.0 \%$ yield was reported with eggshell derived heterogenous catalyst in a transesterification of waste oil at a reaction time of $330 \mathrm{~min}, 22.5: 1$ methanol to oil molar ratio, $3.5 \mathrm{wt} \%$ catalyst loading and $65^{\circ} \mathrm{C}$ reaction temperature [39]. The optimal condition established in this study is consistent with the lowest value reported with a significant high FAME yield. The requirement of longer reaction time, temperature and high amount of methanol/oil ratio and catalyst as reported in the above conditions and others in literature makes operation condition of FAME production simple and cheaper.

\subsection{Evaluation of the Developed Models}

The statistical parameters of the model were computed through the coefficient of determination $\left(\mathrm{R}^{2}\right)$, adjusted $\mathrm{R}^{2}$ and predicted $\mathrm{R}^{2}$, which gave $0.9828,0.9606,0.9249$. The value of $\mathrm{R}^{2}$ is close to 1 which indicates reasonable agreement between the actual and predicted values. The $\mathrm{R}^{2}$ and adjusted $\mathrm{R}^{2}$ of the obtained model demonstrate good agreement between them with acceptable difference of 0.022 , which is lower than the maximum allowable difference of 0.2. The model was also justified with the low coefficient of variance $(1.10 \%)$ and the standard deviation (0.985) from the experimental result.

\subsection{Physicochemical Properties of UVOME}

The physicochemical characterization of UVOME was determined and compared with the ASTM D6751 and EN 14214. The results specified in Table 6 showed that the measured properties of UVOME such as density, viscosity, acid value, iodine value, cetane number and the calorific value are within the limit specified by the American and European standards. Density as one of the important properties of biodiesel has its significant effect on fuel atomization in airless combustion system [9]. From the ASTM and EN standards, the density of biodiesel is in the range of $0.86-0.9\left(\mathrm{~kg} / \mathrm{m}^{3}\right)$. The density of UVOME was $0.862 \mathrm{~kg} / \mathrm{m} 3$, which is within the standard range and other ones reported in literature from bio-base catalyst: [16] reported a density of $0.854 \mathrm{~kg} / \mathrm{m}^{3}$ in FAME produced from sunflower oil using waste sesamum indicum plant. A density of $896 \mathrm{~kg} / \mathrm{m}^{3}$ was reported in FAME produced from kariya seed oil using calcined kola pod husk [4]. In a study carried out by [13], density of 0.8606 $\mathrm{kg} / \mathrm{m}^{3}$ was reported in soybeans biodiesel using waste brassica nigra plant. Palm kernel methyl ester was produced using banana peels at a density of $0.86 \mathrm{~kg} / \mathrm{m}^{3}$ was recorded [34]. Viscosity is another vital property of any biodiesel fuel. The standard range for viscosity is from $1.9-6.0 \mathrm{~mm}^{2} / \mathrm{s}$. UVOME viscosity with CCPP was $4.52 \mathrm{~mm}^{2} / \mathrm{s}$, which is also satisfactory with limit standard range by ASTM and EN. The viscosity obtained is also in the same range with the biodiesel obtained from other biomass heterogenous catalysts in literature; [15] reported the viscosity of 5.0 $\mathrm{mm}^{2} / \mathrm{s}$ in neem biodiesel with plantain peels, [34] reported 4.3 $\mathrm{mm}^{2} / \mathrm{s}$ using banana peels in palm kernel biodiesel, [17] also reported $5.3 \mathrm{~mm}^{2} / \mathrm{s}$ in neem biodiesel using coco pod husk. Acid number is another characteristic of biodiesel which can cause corrosion in internal part of the engine. The ASTM and EN standard limit for acid number is strictly on 0.5 max, acid number above 0.5 is not acceptable by the standard. UVOME acid number was 0.38 $\mathrm{mg} / \mathrm{KOH} / \mathrm{g}$ which is lower than the maximum stipulated limit by the international standard and recommendable for biodiesel fuel. Cetane number is another important characteristic in a fuel which affects the fuel ignition after injection. The cetane number of UVOME was 58.10 which is well above the minimum of international standards and close to the value reported by [13, 14]. The calorific value of UVOME was found to be $42.76 \mathrm{MJ} / \mathrm{kg}$, which in agreement with the reported values of 40.30, 43.19 and 48.7 $\mathrm{MJ} / \mathrm{kg}$ in literature [14, 16, 17].

\subsection{Reusability of the CCPP Catalyst}

The test of reusability of CCPP catalyst was done at optimised condition for UVOME production (Fig. S3). The method of [4] was adopted in the recovery process of the used catalyst. Centrifugation method was used to achieve the catalyst recovery from the separation process of the reaction mixture, and then used without any further calcination. A considerable decrease in yield of each cycle was observed and $88.5 \%$ yield was obtained at the end of the 3th cycle. This may be due to the intermolecular break down of bonds in catalyst-methanol/oil molar ratio, as an effect of leaching of the active site into the reaction mixture, which causes the deficiency of catalytic activity of the catalyst [24]. It might also occur as a result of adsorption of organic molecules when the active surface sites of the catalyst is saturated or clogged [40]. Similar cases of minimal decrease in biodiesel yield has been reported elsewhere with bio-catalyst reusability; a decrease of $2.39 \%$ after 4 cycle was reported, when kola nut pod husk was used in transesterification of kariya seed oil [4], a decrease of $24 \%$ yield after 4 cycle with elephant-ear pod husk as a catalyst in transesterification of neem-rubber blend oil was reported by [24], [12] reported the decrease of FAME from 97.3 to $80 \mathrm{wt} \%$ after five cycle when calcined tucuma peels was used as a catalyst. However, a rare case of drastic decrease of $46.79 \%$ in FAME yield after 3 cycle was report by [25] when burnt banana peel was used as a catalyst in soybeans biodiesel conversion. This was observed as the possibly effect of lack of calcination of the burnt banana peels at high temperature to prevent much leaching.

\section{Conclusions}

Heterogenous catalysts derived from agro waste materials are simple to develop, eco-friendly, renewable, cost effective and highly efficient. The derived catalysts also indicate good performance when deployed in the conversion of used vegetable oil to biodiesel. In this work, easily available agro-waste derived heterogeneous catalyst was explored from Carica papaya peels for biodiesel syn- 
thesis from used vegetable oil (UVO). The conversion was carried out through optimized parameters in the transesterification process using the developed CCPP at $700^{\circ} \mathrm{C}$ for $4 \mathrm{~h}$. Characterization of the ash catalyst confirmed the mesoporous nature of material. The presence of high content of K as indicated by EDX (@ 30.74\%), XRD and FT-IR in the form of chloride, sulphate, carbonate and oxide revealed its key role as the active elements responsible for the used vegetable oil conversion to biodiesel. The catalyst was capable of converting up to a maximum of $97.50 \mathrm{wt} \%$ of biodiesel yield, under the parametric optimised condition established by Box Behnken design of: the catalyst amount of $3.5 \mathrm{wt} \%$, methanol to oil ratio of 12:1, reaction time of $60 \mathrm{~min}$ at a constant temperature of $65^{\circ} \mathrm{C}$, which by prediction obtained $96.06 \mathrm{wt} \%$. The relationship between the actual and predicted yields suggest that the values were in sufficient agreement and well fitted with the model with good prediction of the response for the system in the range studied. The efficacy of CCPP was tested up to the third cycle of reaction with 88.5 wt\% yield of UVO conversion at the last reaction, without much loss in the catalytic activity. The properties of the biodiesel produced were within the ASTM D6751 and EN 14214 standard specification. It could therefore be concluded that the prepared heterogenous catalyst from Carica papaya peels could serve as efficient and effective catalyst in biodiesel production at industrial level.

\section{Acknowledgment}

The authors would like to appreciate the financial assistance of the National Research Foundations (NRF) of South Africa under grant number 110917.

\section{Author Contributions}

A.O. (Ph.D student) conducted all the experiments and wrote the manuscript. A.C. (Ph.D.) supervised the study, revised the manuscript and managed the editorial process of the manuscript. P.M. (Professor) supervised the study, revised the manuscript.

\section{References}

1. Sahar, Sadaf S, Iqbal J, et al. Biodiesel production from waste cooking oil: An efficient technique to convert waste into biodiesel. Sustain. Cities Soc. 2018;41:220-226.

2. Balajii M, Niju S. A novel biobased heterogeneous catalyst derived from Musa acuminata peduncle for biodiesel production - Process optimization using central composite design. Energy Convers. Manag. 2019;189:118-131.

3. Etim AO, Musonge P, Eloka-Eboka AC. Effectiveness of biogenic waste-derived heterogeneous catalysts and feedstock hybridization techniques in biodiesel production. Biofuels Bioprod. Biorefin. 2020;14:620-649.

4. Betiku E, Okeleye AA, Ishola NB, Osunleke AS, Ojumu TV. Development of a novel mesoporous biocatalyst derived from kola nut pod husk for conversion of kariya seed oil to methyl esters: A case of synthesis, modeling and optimization studies. Catal. Letters. 2019;149:1772-1787.

5. Martial-Didier AK, Hubert KK, Jean PKE, Kablan T. Phytochemical properties and proximate composition of papaya (Carica papaya L. var solo 8) peels. Turkish J. Agric. - Food Sci. Technol. 2017;5:676-680.

6. Moses MO, Olanrewaju MJ. Proximate and selected mineral composition of ripe pawpaw (carica papaya ) seeds and Skin. J. Sci. Innov. Res. 2018;7:75-77

7. Mohamad M, Ngadi N, Wong SL, Jusoh M, Yahya NY. Prediction of biodiesel yield during transesterification process using response surface methodology. Fuel 2017;190:104-112.

8. Borah MJ, Das A, Das V, Bhuyan N, Deka D. Transesterification of waste cooking oil for biodiesel production catalyzed by $\mathrm{Zn}$ substituted waste egg shell derived $\mathrm{CaO}$ nanocatalyst. Fuel 2019;242:345-354

9. Hoseini SS, Najafi G, Sadeghi A. Chemical characterization of oil and biodiesel from Common Purslane (Portulaca) seed as novel weed plant feedstock. Ind. Crops Prod. 2019;140.

10. Rahimi M, Aghel B, Alitabar M, Sepahvand A, Ghasempour HR. Optimization of biodiesel production from soybean oil in a microreactor. Energy Convers. Manag. 2014;79:599-605.

11. Gohain M, Laskar K, Phukon H, Bora U, Kalita D, Deka D. Towards sustainable biodiesel and chemical production: Multifunctional use of heterogeneous catalyst from littered Tectona grandis leaves. Waste Manag. 2020;102:212-221.

12. Mendonça IM, Paes OARL, Maia PJS, et al. New heterogeneous catalyst for biodiesel production from waste tucumã peels (Astrocaryum aculeatum Meyer): Parameters optimization study. Renew. Energy. 2019;130:103-110.

13. Nath B, Das B, Kalita P, Basumatary S. Waste to value addition: Utilization of waste Brassica nigra plant derived novel green heterogeneous base catalyst for effective synthesis of biodiesel. J. Clean. Prod. 2019;239:118-112.

14. Betiku E, Akintunde AM, Ojumu TV. Banana peels as a biobase catalyst for fatty acid methyl esters production using Napoleon's plume (Bauhinia monandra) seed oil: A process parameters optimization study. Energy 2016;103:797-806.

15. Etim A, Betiku E, Ajala S, Olaniyi P, Ojumu T. Potential of ripe plantain fruit peels as an ecofriendly catalyst for biodiesel synthesis: Optimization by artificial neural network integrated with genetic algorithm. Sustainability 2018;10:707.

16. Nath B, Kalita P, Das B, Basumatary S. Highly efficient renewable heterogeneous base catalyst derived from waste Sesamum indicum plant for synthesis of biodiesel. Renew. Energy. 2019;151:295-310.

17. Betiku E, Etim AO, Pereao, Ojumu TV. Two-step conversion of neem (Azadirachta indica) seed oil into fatty methyl esters using a heterogeneous biomass-based catalyst: An example of cocoa pod husk. Energy Fuels. 2017;31:6182-6193.

18. Gohain M, Devi A, Deka D. Musa balbisiana colla peel as highly effective renewable heterogeneous base catalyst for biodiesel production. Ind. Crops Prod. 2017;109:8-18.

19. Marwaha A, Rosha P, Mohapatra SK, Mahla SK, Dhir A. Biodiesel production from Terminalia bellerica using eggshell-based green catalyst: An optimization study with response surface methodology. Energy Reports. 2019;5:1580-1588. 
20. Selvaraj R, Moorthy IG, Kumar RV, Sivasubramanian V. Microwave mediated production of FAME from waste cooking oil: Modelling and optimization of process parameters by RSM and ANN approach. Fuel. 2019;237:40-49.

21. Latchubugata CS, Kondapaneni RV, Patluri KK, Virendra U, Vedantam S. Kinetics and optimization studies using Response Surface Methodology in biodiesel production using heterogeneous catalyst. Chem. Eng. Res. Des. 2018.

22. Harsha Hebbar HR, Math MC, Yatish KV. Optimization and kinetic study of $\mathrm{CaO}$ nano-particles catalyzed biodiesel production from Bombax ceiba oil. Energy. 2018;143:25-34.

23. Gohain M, Devi A, Deka D. Musa balbisiana Colla peel as highly effective renewable heterogeneous base catalyst for biodiesel production. Ind. Crop. Prod. 2017;109:8-18.

24. Falowo OA, Oloko-Oba IM, Betiku E. Biodiesel production intensification via microwave irradiation-assisted transesterification of oil blend using nanoparticles from elephant-ear tree pod husk as a base heterogeneous catalyst. Chem. Eng. Process. - Process Intensif. 2019;140:157-170.

25. Pathak G, Rajkumari K, Rokhum L. Wealth from waste: M. acuminata peel waste-derived magnetic nanoparticles as a solid catalyst for the Henry reaction. Nanoscale Adv. 2019;1(3): 1013-1020.

26. Adepoju TF. Optimization processes of biodiesel production from pig and neem (Azadirachta indica a. Juss) seeds blend oil using alternative catalysts from waste biomass. Ind. Crop. Prod. 2020;149:112-334.

27. Vadery V, Narayanan BN, Ramakrishnan RM, Kochiyil S, Sugunan S, Narayanan DP. Room temperature production of jatropha biodiesel over coconut husk ash. Energy 2014;70:588594.

28. Dos Santos CM, de Abreu CMP, Freire JM, Queiroz ER, Mendonça MM. Chemical characterization of the flour of peel and seed from two papaya cultivars. Food Sci. Technol. 2014;34:353-357.

29. Gohain M, Laskar K, Paul AK, et al. Carica papaya stem: A source of versatile heterogeneous catalyst for biodiesel production and C-C bond formation. Renew. Energy. 2020;147:541555

30. Pathak G, Das D, Rajkumari K, Rokhum L. Exploiting waste: Towards a sustainable production of biodiesel using: Musa acuminata peel ash as a heterogeneous catalyst. Green Chem. 2018;20:2365-2373

31. Dhawane SH, Kumar T, Halder G. Parametric effects and optimization on synthesis of iron (II) doped carbonaceous catalyst for the production of biodiesel. Energy Convers. Manag. 2016;122:310-320

32. Sharma M, Ali A, Puri SK, Tuli DK. Wood ash as a potential heterogeneous catalyst for biodiesel synthesis. Biomass Bioenergy. 2012;41:94-106.

33. Uprety BK, Chaiwong W, Ewelike C, Rakshit SK. Biodiesel production using heterogeneous catalysts including wood ash and the importance of enhancing byproduct glycerol purity. Energy Convers. Manag. 2016;115:191-199.

34. Odude VO, Adesina AJ, Oyetunde OO, et al. Application of agricultural Wwste-based catalysts to transesterification of esterified palm kernel oil into biodiesel : A Case of banana fruit peel versus cocoa pod husk. Waste Biomass Valori. 2019;10:877888.

35. Lathiya DR, Bhatt DV, Maheria KC. Synthesis of sulfonated carbon catalyst from waste orange peel for cost effective biodiesel production. Bioresour. Technol. Reports. 2018;2:69-76.

36. Dhawane SH, Kumar T, Halder G. Recent advancement and prospective of heterogeneous carbonaceous catalysts in chemical and enzymatic transformation of biodiesel. Energy Convers. Manag. 2018;167:176-202

37. Verma P, Sharma MP. Review of process parameters for biodiesel production from different feedstocks. Renew. Sustain. Energy Rev. 2016;62:1063-1071

38. Chitsaz H, Omidkhah M, Ghobadian B, Ardjmand M. Optimization of hydrodynamic cavitation process of biodiesel production by response surface methodology. J. Environ. Chem. Eng. 2018;6:2262-2268.

39. Tshizanga N, Aransiola EF, Oyekola O. Optimisation of biodiesel production from waste vegetable oil and eggshell ash. South African J. Chem. Eng. 2017;23:145-156.

40. Rahman WU, Fatima A, Anwer AH, et al. Biodiesel synthesis from eucalyptus oil by utilizing waste egg shell derived calcium based metal oxide catalyst. Process Saf. Environ. Prot. 2019;122:313-319. 